\title{
ATRAPADOS EN LA RED: LOS MUNDOS VIRTUALES EN LA POESÍA ESPAÑOLA RECIENTE
}

Trapped in the Net: the virtual worlds in recent Spanish poetry

\author{
LUIS BAGUÉ QuíLEZ \\ UNIVERSIDAD DE MURCIA (ESPAÑA) luisbaguequilez@gmail.com
}

\section{RECIBIDO: 28 DE ENERO DE 2018 ACEPTADO: 6 DE MARZO DE 2018}

RESUMEN: Este artículo se centra en la presencia del mundo virtual en un conjunto de poetas españoles nacidos a partir de 1980, a los que se ha considerado los primeros nativos digitales. Los miembros de esta promoción incorporan selectivamente procedimientos retóricos y estrategias discursivas que se inspiran en las nuevas realidades del ciberespacio, entendido como tema poético y como dispositivo estructural. En concreto, se analizan tres representaciones en las que la vida privada conecta con la experiencia tecnológica: el papel de Internet como catalizador de la reflexión metapoética; la labor que cumplen las redes sociales en la configuración de la identidad contemporánea; y la influencia que tienen ciertos buscadores, enlaces y aplicaciones móviles en las relaciones interpersonales y en las transacciones sociales que determinan el universo poscapitalista del siglo XXI. Más integrados que apocalípticos, los poetas-internautas que comparecen en estas páginas ya no confunden el medio con el mensaje ni se dejan tentar por las quimeras virtuales, sino que han hecho de la navegación por la Red un emblema colectivo, una seña de identidad y un lugar estético que actualiza y revitaliza los tópicos eternos.

PALABRAS CLAVE: mundo virtual, redes sociales, nuevas tecnologías, poesía española reciente, reflexión metapoética, identidad contemporánea.

ABSTRACT: This paper focuses on the presence of the virtual world in some Spanish poets born since 1980, who have been considered the first digital natives. The members of this promotion selectively incorporate rhetorical procedures and discursive strategies inspired by the new realities of cyberspace, which is understood both as a poetic theme and as a structural device. Specifically, three representations in which private life connects with technological experience are analysed: the role of the Internet as a catalyst for meta-poetic reflection; the function of social networks in the configuration of contemporary identity; and the influence that certain platforms, links and mobile applications have on the interpersonal relationships and social transactions determining the post-capitalist universe of the early 21 st century. More integrated than apocalyptic -in Eco's terms-, the Internet-poets appearing in these pages neither confuse the medium with the message anymore, nor let themselves be tempted by virtual chimeras, but they have transformed their Internet browsing into a collective emblem, a sign of identity and an aesthetic commonplace that updates and revitalizes the eternal topoi.

KEYWORDS: virtual world, social networks, modern technologies, meta-poetic reflection, contemporary identity.

Bagué Quílez, Luis.

"Atrapados en la red: los mundos virtuales en la poesía española reciente".

Kamchatka. Revista de análisis cultural 11 (Julio 2018): 331-349

DOI: 10.7203/KAM.11.11424 ISSN: 2340-1869

Monográfico LECTURAS DEL DESIERTO: NUEVAS PROPUESTAS POÉTICAS EN ESPAÑA 


\section{INFOXICACIÓN E-LÍRICA ${ }^{1}$}

La hiperestimulación digital que algunos críticos aprecian a mediados de la década del dos mil puede contemplarse como el resultado de una profecía cuyos orígenes se remontan a los años sesenta. En efecto, las famosas predicciones de McLuhan ([1964] 1996) acerca de la progresiva descentralización cultural se sustentaban en una aceleración histórica que pronto se extendería a todas las parcelas de la realidad cotidiana. Así, mientras que los años setenta se corresponden con la eclosión de los nuevos medios de comunicación, los ochenta muestran una apabullante oferta orientada a satisfacer los apetitos pulsionales de la audiencia de masas. La especialización de la prensa, la radio y la publicidad, la aparición de la industria de los videoclips, la renovación de la escucha musical gracias al formato walkman o la multiplicación de canales televisivos eran solo los síntomas superficiales de que algo se movía en el tablero de la aldea global. No obstante, estos avances tecnológicos se toparon de bruces con un problema que impedía que el cambio de soporte se tradujera en un cambio de paradigma: la falta de interacción con el sujeto-usuario, condenado a interpretar el papel de convidado de piedra o a ejercer de espectador pasivo de la revolución posindustrial (Castells, [1996] 1997: 369-374). Surgida a lo largo de los años noventa, la constelación electrónica vinculada a Internet contribuirá a paliar y, finalmente, a cubrir esa carencia. La evolución desde la primitiva ARPANET - un instrumento de comunicación militar estadounidense ante la "fría" amenaza soviética- hasta el actual sistema flexible de redes (World Wide Web) ha ido acompañada de tres factores: la digitalización de enormes cantidades de información; la fluidez de la comunicación, a través de terminales de ordenador interconectadas; y la noción de "hipertexto" (Quinto, 2013: 194), venida a sacudir una vez más los ya maltrechos cimientos de la galaxia Gutenberg.

Si preferimos ceñirnos a los datos objetivos, en 2017 se calcula que hay alrededor de 3773 millones de usuarios de Internet y 2789 millones de usuarios de redes sociales (capitaneadas por Facebook, Instagram y Twitter), y ello a pesar de que más de la mitad de la población mundial sigue sin disponer de acceso a la Red. En cuanto a su implantación en España, la página web del Instituto Nacional de Estadística aporta información relativa al último trimestre de 2016, según la cual el 80,6\% de la población entre los 16 y los 74 años habría hecho alguna incursión en el ciberespacio durante este periodo; un porcentaje que se eleva hasta el 98,4\% al poner el foco en la franja de edad comprendida entre los 16 y los 24 años. $^{2}$

La definitiva adopción de la perspectiva reticular promovida por Internet -lo que Brea (2007) denominó "cultura RAM" - influye en los parámetros estéticos de los nuevos bardos, en una encrucijada en la que convergen la poesía en la Red y la poesía en torno a la Red. La primera concede prioridad al medio de difusión, aunque sus consecuencias afectan a la configuración del campo literario, que habría de ampliar sus márgenes para acoger un tipo de creaciones que pretenden recalificar el terreno productivo y redemocratizar la cadena de distribución comercial. Sin embargo, la "consolidación de una comunidad de lectores de poesía con intereses muy

\footnotetext{
* Este trabajo es un resultado del Programa "Ramón y Cajal" (RYC-2014-15646), del Ministerio de Economía y Competitividad. Asimismo, se enmarca en el Proyecto de Investigación "Poéticas de la Transición (1973-1982) (FFI2017-84759-P).

2 Véase el documento "Población que usa Internet (en los últimos tres meses)".
} 
distintos a los auspiciados entonces por el mundo editorial", como sostiene Rodríguez-Gaona (2010: 56), corre el riesgo de sustituir un filtro elitista o mercantilista por la ausencia de filtros. ${ }^{3}$ Basta con circular por las autovías del ciberespacio para comprobar que la proliferación de páginas, blogs y portales dedicados a la poesía rara vez implica una reescritura crítica de las gramáticas creativas por las que se rigen los textos impresos. La "suspensión de la autoridad", según el concepto de Žižek (2006: 207-244) que retoma Martín Gijón (2011: 357) para aludir a la volatilidad de la poesía en Internet, genera una sensación de libertad absoluta provocada por la supresión de toda jerarquía (Prieto de Paula, 2010: 34). De hecho, las fronteras difusas del mapa virtual permiten cuestionar incluso la categoría de "lo poético" ante la avalancha de formas interdisciplinares que se adscriben al perímetro de lo que empieza a conocerse como e-vanguardia o e-juglarias.4 poesía visual (videopoesía, fotopoesía, holopoesía), poesía sonora (spoken word, perfopoesía), micropoesía o poesía de generación automática (PAC, flarf) (Rodríguez-Gaona, 2010: 71-72; Scarano, 2014: 21).5

A pesar del creciente interés que despiertan estos géneros performativos, a menudo más cercanos a las artes escénicas o plásticas que a las destrezas verbales, en este artículo me centraré en la otra vertiente enunciada: la poesía en torno a Internet. Con esta finalidad, partiré de dos acercamientos complementarios a este fenómeno: por un lado, una aproximación temática, que contempla la Red como núcleo referencial, paisaje emotivo o decorado de los poemas; por otro lado, una aproximación estilística, que trata de explotar en una obra impresa las posibilidades textovisuales que favorecen las nuevas tecnologías (Díaz Rosales, 2011: 285; Quinto, 2013: 202). Un somero repaso a la poesía española de los últimos años evidencia que Internet se ha ido asomando a los versos cada vez con mayor asiduidad. Ya algunos autores de los noventa introdujeron la banda ancha y los artilugios digitales como emblemas de una sociedad infoxicada que polemizaba con la tradición grecolatina. La contigüidad de lo clásico y lo posmoderno es un motivo recurrente en los versos de Aurora Luque y Juan Antonio González Iglesias: si a la primera pertenecen "Al encontrar en Internet un mapa del mundo subterráneo" (Camaradas de Ícaro, 2003) o "Rap para la romería de Steve Jobs" (Personal \& político, 2015), el segundo ha vinculado los textos sagrados con la sacralización consumista - "Leo a Tomás de Aquino en el Smartphone" (Confiado, 2015)-, y ha argumentado que el beatus ille contemporáneo consiste en escapar de la tiranía de las redes sociales. Frente a este cóctel mezclado y agitado, otros autores, nacidos a finales de los sesenta o comienzos de los setenta, han invocado el nombre de Internet como mantra de una posmodernidad lúdica y palimpsestuosa. Ensayos como Afterpop (2007), de

\footnotetext{
3 El reportaje "La poesía estalla en las redes", publicado en el suplemento "Babelia" del diario El País, ilustra esa euforia tecnológica que resalta exclusivamente el cauce de divulgación y su capacidad para expandirse "por la web a través de blogs, tuits, tumblr y YouTube" (Aguilar, 2014: s/p).

4 Según certifica Jauralde Pou (2014: 25), la nueva poesía surgida en la Red reitera los viejos tics de las vanguardias históricas: "La inquietud y los motivos son los mismos; los elementos que se repiten ahora, sin embargo, no son exactamente idénticos: acceso libre de verdaderas masas de creadores al campo de la difusión [...]; ruptura o transformación de todo tipo de fronteras que vinieran impuestas por la tradición artística [...]; utilización de técnicas y usos hasta ahora desconocidos (vídeos, creación por ordenador)".

5 La poesía asistida por computadoras (PAC), o los generadores automáticos de poesía (GAP), basados en una combinación aleatoria de estilemas con la intención de producir un discurso "poético" (Labrador Méndez, 2006: 55-78), tienen un precedente en las prácticas de Oulipo, como los Cien mil millones de poemas (1961) de Raymond Queneau.
} 
Eloy Fernández Porta, y Postpoesía (2009), de Agustín Fernández Mallo, propugnan una vuelta (de tuerca) a las relaciones conflictivas entre alta y baja cultura, ahora mediatizadas por la iconografía tecnológica y la fragmentariedad asociativa. ${ }^{6}$ Las secuencias "enredadas" que Vicente Luis Mora incorpora en Mester de Cibervía (2000), los flashes escópicos que Fernández Mallo disemina en Carne de píxel (2008), los haikus disfrazados de enlace web que Javier Moreno enhebra en Renacimiento (2009) y el haiku en código binario que Jesús Jiménez Domínguez transcribe en Fundido en negro (2007) demuestran que la Red funciona como un laboratorio creativo, a la vez taller de fabricación de metáforas y planta de reciclaje de los dialectos de las puntocom (Bagué Quílez y Santamaría, 2013: 29-31; Quinto, 2013: 203). Sin embargo, el peligro de esta experimentación con los metalenguajes informáticos radica en la "obsolescencia programada" de unas obras dependientes de un entorno maleable, proclive a convertir en flagrantes anacronismos cualesquiera novísimas alusiones a dispositivos, páginas web o aplicaciones. ${ }^{7}$

Este es el contexto en el que desembarcan los poetas nacidos a partir de 1980. Se trata de la primera promoción de nativos digitales: mientras que los mayores accedieron a Internet en su adolescencia, los que vinieron al mundo en los años noventa han vivido inmersos en un jardín virtual poblado de pantallas que se bifurcan, emoticonos de WhatsApp y sonidos rítmicamente acompasados, procedentes de la mensajería instantánea. La asimilación de estos autores a una escritura con zona wifi (Morante, 2016: 11) justifica algunos de los rótulos que se han propuesto para la partida de bautismo grupal: generación Blogger (González, 2010), generación Google (Rodríguez-Gaona, 2010: 237) o generación Enter (Corral Cañas, 2014: 86). ${ }^{8}$ No obstante, si descendemos al análisis de libros o antologías no se observa un espectacular aumento cuantitativo de la presencia de la Red en los versos, sino más bien un cambio cualitativo: Internet ha pasado de constituir un elemento de atrezo más o menos rupturista a insertarse con naturalidad en el universo referencial y a entroncar con unas señas de identidad personales y comunitarias.

La navegación por la web ya no es esa realidad "otra" que nos fascina por su exotismo, sino un ingrediente de la vida cotidiana. El sujeto-usuario (bomo navigator, homo ciberneticus u homo sampler) se pasea por los mapas de bytes, los recintos pixelados y los circuitos de memoria con la misma desenvoltura con la que el flâneur de Baudelaire lo hacía por el París del siglo XIX (Bagué

\footnotetext{
6 En opinión de Fernández Mallo (2012: 34), la fragmentación es una cualidad que comparten la literatura contemporánea y la cibercultura: "Vivimos en la fragmentación de mensajes no porque hayamos vulgarizado el mundo, sino al contrario: cada fragmento, cada unidad, es un producto ya en sí complejo [...]. [Son fragmentarios] cada imagen, cada frase publicitaria, cada eslogan, cada destello láser, cada programa de TV".

${ }^{7}$ La fagocitación tecnológica, que degrada rápidamente en arqueología lo que poco antes resultaba innovador, puede ejemplificarse incluso en los títulos de ciertas obras, como el poema "A mi walkman" (¿Estás seguro de que no nos siguen?, 2003), de Antonio Portela, o el libro SMS (2007), de Daniel Aldaya.

8 A la cohesión generacional del grupo, más compacto que el de sus predecesores en la escena lírica, han contribuido antologías de lanzamiento que aprovechan la ductilidad de las redes y que transitan por los pasadizos entre la escritura material y la proyección virtual (Rosal Nadales, 2016: 185-186), como La manera de recogerse el pelo. Generación Blogger (2010), de David González, o Tenían veinte años y estaban locos (2011), de Luna Miguel, que expande su nómina en el blog homónimo gracias a actualizaciones sucesivas: < http://estabanlocos.tumblr.com/ >. En este sentido, Luna Miguel no vacila en afirmar que el acontecimiento aglutinador de estos autores es "Internet. Muchos comenzaron sus andanzas en la literatura desde la blogosfera" (en Corral Cañas, 2014: 86-87). Curiosamente, a esa orientación ciberespacial parecen haber renunciado antologías más recientes, como Re-generación. Antología de poesía española (2000-2015) (2016), recopilada por José Luis Morante, o Nacer en otro tiempo. Antología de la joven poesía española (2016), editada por Miguel Floriano y Antonio Rivero Machina.
} 
Quílez, 2014: 7). Las horas perdidas en los buscadores de Internet -glosando un título de Roger Wolfe- no solo expresan una vivencia global; además, construyen una experiencia singular (Castells, [1996] 1997: 406). Con todo, la Red ha dejado de identificarse con el altavoz solipsista desde el que se manifiesta una militancia política, se exhibe una imagen social o se articula una actitud artística. En su interior se gestan representaciones colectivas ligadas a prácticas de enunciación a las que no resulta ajeno el discurso lírico (Corral Cañas, 2014: 78).

Todo ello cristaliza en una conciencia estética inédita hasta el momento. Mientras que el ámbito de recepción se caracteriza por estrechar los lazos entre el escritor y sus lectores, el horizonte creativo dota de empaque digital a preocupaciones habituales en la poesía contemporánea, como la reflexión metapoética, la indagación en la intimidad o la denuncia de las desigualdades sociales. Así, en el siguiente apartado de este artículo me detendré en composiciones en las que los formatos tecnológicos sirven como catalizadores de una inquietud metadiscursiva que se contagia de manera viral a través de las pantallas encendidas. En "Poética de la tecla insert" (31 poemas, 2010), de María Salgado; "A un Garrard de cuerda del '65 comprado en ebay" (La mezcla confusa, 2011), de Ben Clark; "Práctica oral" (Un lugar en el que nunca be escrito, 2013), de Aitor Francos; y "Alejandrino" (Accidente, 2017), de Camino Román, las terminaciones nerviosas que activan la escritura se alían con las terminales electrónicas de las que se nutre Internet. Un paso más allá, en la tercera sección abordaré el papel de las redes sociales, inspiradoras de roles y patrones subjetivos en un entorno generacional definido por la provisionalidad de las certezas y la falta de expectativas. "Alicia en el País de las Redes Sociales" (Pertinaz freelance, 2016), de Sergio C. Fanjul, podría erigirse en el manifiesto de una sensibilidad adiestrada en la práctica de Facebook y Twitter, a la que también se acercan los perfiles (reales y virtuales) de Víctor Peña Dacosta o Berta García Faet. El cuarto apartado se dedicará a la influencia de ciertos buscadores, enlaces y aplicaciones en el marco poscapitalista del siglo XXI, como se advierte en "Google" (Los idiomas comunes, 2010), de Laura Casielles; "Google Maps" (en la antología Re-generación, 2016), de Diego Álvarez Miguel; y "Lost in Google Translate" (inédito, en el blog < arrebatosaliricos.blogspot.com/>), de Víctor Peña Dacosta. Por último, en las conclusiones se recapitularán los principales resultados obtenidos.

\section{NuEVOS MESTERES DE CIBERVÍA: GOLPE (DE TECLADO) A GOLPE (DE TECLADO)}

La experiencia de escritura actual está unida al manejo de un procesador de textos y a la inmersión - a pulmón libre- en los mares de la Red. Si la primera poesía de Claudio Rodríguez se acompasaba a sus recorridos andariegos por tierras de Zamora y la poesía urbana de Luis García Montero respondía a los avances y retrocesos de un individuo que cruzaba avenidas, vadeaba semáforos y atravesaba pasos de cebra, no es extraño que los jóvenes poetas acomoden sus versos a la velocidad táctil de un mensaje de WhatsApp o al rítmico parpadeo del ordenador portátil. El medio digital se ha convertido en un recurso primario, inseparable del acto creativo (Corral Cañas, 2014: 87). Otro asunto es discernir hasta qué punto ese canal influye en la hibridación intertextual o incluso en la disposición de los poemas en la página. Sin entrar en el coto vedado de la poesía visual, existen precedentes de un modelo que rompe con la tradicional "caja" alineada a la izquierda (Mora, 2018). Desde que Mallarmé tirara sus dados, la tipografía y la topografía se conciben como estructuras dinámicas, susceptibles de sufrir alteraciones. Por 
ejemplo, La marcha de 150.000.000 (2009), de Enrique Falcón, reproduce la percepción simultaneísta de la web, al presentarse como un magma torrencial del que surgen ramificaciones a modo de notas al margen o hipervínculos que aportan información adicional, corrigen o contradicen lo dicho, y enriquecen el contenido con apuntes líricos. No obstante, a pesar de algunas salvedades -como Julia Piera, María Eloy-García, Marcos Canteli, Julio César Galán o Juan Andrés García Román, de entre los nacidos en los setenta-, esta senda intermedial no ha sido muy transitada en los últimos años, y tampoco parece que la poesía reciente vaya a discurrir mayoritariamente por tales derroteros.

A medio camino entre lo textual y lo hipertextual se sitúa el discurso dialógico de María Salgado (Madrid, 1984), en el que la oralidad es el punto de partida -el repertorio del que la autora extrae su materia prima- y el punto de llegada - ya que el proceso creativo solo culmina con el recitado o con la escenificación pública- (Mohedano Ruano, 2016: 167). Las peculiaridades del "habla escrita" de Salgado se desarrollan en el siguiente fragmento de "Poética de la tecla insert", en el que la desconexión sintáctica, las interferencias semánticas y el particular uso de la puntuación entroncan con la lógica sincopada y elíptica a la que Umberto Eco ([1964] 1990) bautizó con el ocurrente sintagma de cogito interruptus:

\section{POÉTICA DE LA TECLA INSERT [FRAGMENTO]}

(poética de tecla insert)

memorizo antes de escribir a no ser que escriba antes de memorizar; escritura sobre escritura, paso antes que huella, paso que se come las huellas, pie que se muerde los puños, niño que no nace, viejo que rejuvenece Escribir o morir alternativamente, joh payador!

(poética de insert-coin)

escribo sin memorizar porque todo lo que no sé se guarda en la hucha de mi escritura; escritura que se combina con números de suerte en la máquina trucada; escritura sobre vidrio, retraso en la madera; escritura prohibida, vasos de papel en el campo de presos de Guantánamo

Oh payador, el mundo se escribe sobre una transacción cerrada en un baldío

(poética koiné)

los disturbios de anoche en Yvelines recuerdan a los de antesdeanoche en Villiers-le-Bel y a los de dos años atrás en la columna suburbial francesa tags de transmisión del post: Banlieue, Sarkozy, Marsella, Fuego, Citoyens, hijos de la patria, payador, sabed: que el jour de gloire est arrivé, que viene el tiempo de los signos mudos luminosos Escritura en el efímero en el páramo en la sierpe $[\ldots]$ (Salgado, 2010: 38-39)

La mención reiterada del payador - el cantor latinoamericano que improvisa versos acompañado de una guitarra- parece afiliar la práctica de Salgado a las e-juglarías a las que nos referimos previamente. Sin embargo, más allá de su potencial performativo, el poema actúa como 
una caja de resonancia de conflictos interiores y exteriores, ya que avanza desde la meditación ergotista sobre la función de la escritura hasta el friso colectivo. Las reencarnaciones metafóricas de la "máquina de trovar" de la que hablara uno de los complementarios machadianos -aquí metamorfoseada en tecla de ordenador, tragaperras o signo en el aire- proponen una reflexión sobre el utillaje retórico y una mirada a la retórica del mundo. Frente a la imposibilidad de decir algo que no caiga en el vacío ni se disuelva en el silencio, la autora reivindica una poesía pobre para una sociedad fracturada, que simbolizan ahora el campo de prisioneros de Guantánamo y los disturbios que sacudieron la banlieue parisina en 2005. La retransmisión on line de la violencia, según indican los términos ligados a la redacción de un blog (tag y post), así como la cita de la letra de La Marsellesa, se subordinan a una cosmovisión en la que toda palabra -aunque sea insert- es un arma cargada de valores críticos y vínculos solidarios.

La oralidad subyacente en la obra de María Salgado encuentra un eco subsidiario en "Práctica oral", de Aitor Francos (Bilbao, 1986). A diferencia de la composición anterior, en este caso el desafío reside en verbalizar íntegramente el proceso que conlleva la gestación y preservación de un poema, tras sobrevivir a diversas mutaciones de archivos y formatos:

\section{PRÁCTICA ORAL}

Este poema estuvo en un disquete, en una unidad de disco duro, en un pendrive y en un turbio satélite ruso. Cambió de formato hasta ser

un definitivo PDF (y una copia en Word, esa que no falte). Fue defensor de algunas Olivetti, nunca aprobó mis buenas intenciones

de pasarlo a un portátil de ultimísima generación. Y ahora, que ya es mi amigo, ¿Cómo salir de él (de la red de wifi)

físicamente satisfecho? ¿Y cómo autorizar a un editor actual la reproducción vitro de mi obra? (Francos, 2013: 50)

La distribución estrófica y los versos endecasílabos, propios de un soneto en verso blanco, chocan con el vocabulario informático - disquete, disco duro, PDF, Word, portátil, red, wifi- con el que el autor resume el trayecto biológico y tecnológico que recoge la pieza. Al cabo, la sustitución del contenido (el poema) por el continente (el soporte en el que este se ha conservado) entraña una desacralización de la faceta artística. Así se aprecia en las dos interrogaciones finales, en las que Francos reclama la paternidad de su obra y manifiesta su renuencia a depositarla en manos de quien podría "reproducirla" impunemente para entregarla a los lectores.

El divertimento de Aitor Francos, que dialoga con el esquema del soneto, se prolonga en el juego que plantea Camino Román (Veguellina de Órbigo, León, 1981) a propósito de la métrica 
del alejandrino y de la página web Wikipedia. Esta composición confronta la definición objetiva de alejandrino que se alberga en Wikipedia y la redefinición subjetiva que sugiere la autora, en la que el metro se transformaría en la palabra clave de una historia amorosa:

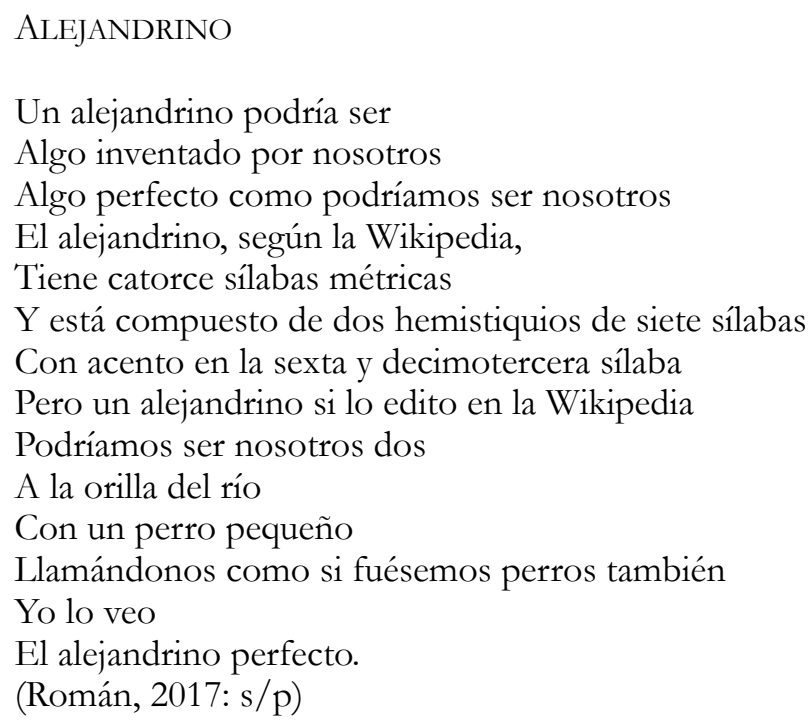

La distancia entre la acepción léxica y la acepción sentimental que la poeta le otorga al término alejandrino se despliega en los respectivos marcos semánticos que habilita el texto: el relativo a la técnica literaria ("sílabas métricas", "hemistiquios") y el relativo a la placidez doméstica compartida ("nosotros dos", "río", "un perro pequeño"). Esa distancia codifica la diferencia que existe entre leer una definición en Wikipedia (una actividad pasiva) y editar el contenido de esa definición (lo que requiere una voluntad activa). El carácter colaborativo de Wikipedia -que, recordemos, se subtitula "La enciclopedia de contenido libre"- favorece la fabulación borgiana según la cual el vocablo sería un túnel secreto hacia una nueva realidad imaginativa: la que emerge tras reemplazar la interacción virtual con Wikipedia por la interacción pasional con el amado. 9

Muy distinto es el enfoque metapoético que exhibe "A un Garrard de cuerda del '65 comprado en ebay", de Ben Clark (Ibiza, 1984), en el que se dan cita tres ingredientes dispares: un reloj de segunda mano comprado por Internet, las subastas de ebay y el oficio del antiguo propietario del reloj, un trabajador de la red de alcantarillado británica. Estos elementos le sirven al autor para postular una poesía nerudianamente impura, manchada de sustancias orgánicas y empeñada en que fluya el discurso a pesar de las obturaciones emotivas:

\footnotetext{
9 La misma Red de redes puede ser en ocasiones la destinataria de la exaltación amorosa. Así ocurre en "Wifi tear us apart again”, de María Sánchez (Córdoba, 1989), también conocida con el nombre artístico de María Mercromina. Más allá del guiño a la canción "Love will tear us apart", de Joy Division, el lenguaje de la poesía erótica se recategoriza gracias la conversión de Internet en un objeto de deseo adictivo y tóxico: "porque yo sí que estoy enamorada estoy infectada estoy completamente colgada del espacio en blanco del buscador de google y de la red" (2015: s/p).
} 


\section{A UN GARRARD DE CUERDA DEL '65 COMPRADO EN EBAY}

He comprado un reloj por Internet.

Su dueño fue un inglés, ya fallecido, que lo recibió por cuarenta inviernos manteniendo el sistema de Aguas público.

Cuarenta años mirando por la mierda.

Procurando que nunca se atascara, que resultara fácil su camino.

Y uno podría decir que lo importante

no es el reloj en sí,

que lo es el gesto,

el abrazo del tiempo y la sonrisa

sutil pero sincera de aquel hombre

tomándose una pinta,

luciendo aquel reloj.

Pero aquí está el objeto, en Salamanca, subastado en ebay, ligeramente

disputado entre un ruso y un francés, sin que al final ninguno se mojara por el hombre que tuvo las rodillas siempre hundidas en agua maloliente. Y la verdad, tampoco yo lo aprecio como quizá el reloj se mereciera.

Y debería hacerlo.

Porque no es tan distinto dedicarse a escribir, procurando que la mierda fluya, que se disperse, cualquier cosa -tú lo decías siempremenos dejar que aquello se te atasque. (Clark, 2011: 19-20)

La isotopía de la suciedad ("mierda", "atascara", "se mojara", "agua maloliente") se asocia con el célebre manifiesto "Sobre una poesía sin pureza", publicado por Neruda en el primer número (1935) de Caballo Verde para la Poesía, en el que se defendía una escritura "gastada como por un ácido por los deberes de la mano, penetrada por el sudor y el humo, oliente a orina y a azucena" (en Lechner, [1968 y 1975] 2004: 449-450). No obstante, Clark introduce varias notas que diversifican el anclaje metaliterario: por un lado, el reloj incorpora resonancias del horaciano tempus fugit, por otro, la alusión a la lonja virtual de ebay y a los compradores que no llegaron a "mojarse" desplaza el eje metapoético hacia un neocapitalismo invisible y tentacular que se camufla detrás de dígitos y nacionalidades. La adquisición del reloj a través de una aplicación electrónica lo despoja de su sentido inicial hasta devaluarlo en una posesión fetichista. Con todo, la cuantiosa información que el autor nos suministra acerca del propietario original y su evocación en el penúltimo verso - "tú lo decías siempre"- nos autorizan a pensar que el sujeto mantenía alguna relación familiar o afectiva con el dueño del reloj. Desde ese punto de vista, "A un Garrad de cuerda...” volvería a dotar al objeto de las cualidades humanas que habría perdido en su viaje por los deshumanizados circuitos de Internet.

En los textos comentados, la Red reubica el contenido metapoético en unas coordenadas novedosas, a pesar de que los temas que suscitan la reflexión teórica no hayan variado sustancialmente. De hecho, la (insalvable) brecha entre la escritura y la realidad social (María 
Salgado) o sentimental (Camino Román), las dudas sobre el origen y la pervivencia de la poesía (Aitor Francos) o la apuesta por un lirismo impuro (Ben Clark) se inscriben en un filón metadiscursivo cultivado con asiduidad desde la promoción del medio siglo. Sin embargo, el canal navegable de Internet - que no protagoniza ninguna composición, pero que cumple un papel relevante en todas ellas- coadyuva a la intención desacralizadora en la que coinciden estos autores: el deseo de restarle gravedad al mensaje mediante el giro irónico que supone hablar de asuntos trascendentes con un vocabulario aprendido en la wifi. ${ }^{10}$

\section{DE PERFIL: POETAS EN EL PAÍS DE LAS REDES SOCIALES}

Desde su asombrosa irrupción a mediados de la década del dos mil, las redes sociales se han transmutado en un escaparate de la intimidad, un repositorio global de noticias y un foro de opinión donde se escucha, en confuso vocerío, el ruido del mundo. La más veterana, Facebook (nacida en 2004), sigue liderando el disputado territorio digital frente a sus competidoras inmediatas, Twitter (lanzada en 2007) e Instagram (surgida en 2010). En pocos años, la plataforma diseñada por Mark Zuckerberg ha sido capaz de atender al mercado de los afectos, proyectar vía streaming "la intrahistoria de nuestro tiempo" (Mora, 2012: 172) y desplegarse como un "periódico total" (174) al alcance de un clic. La interacción de las redes sociales con la sociedad de las redes ha tenido consecuencias imprevistas en el ámbito de las relaciones personales, como Jorge Riechmann (2013: 166) ha resumido en un implacable aforismo titulado "Regla de tres": "La socialidad es a Facebook lo que la felicidad a la Coca-Cola". No en vano, aunque Facebook es un campo abonado para la proliferación de trampantojos, sus devotos continúan esperando con impaciencia la bendición colectiva del "me gusta". Un sitio web que nos invita a seguir y a ser seguidos, que "limita" nuestro círculo de amistades a 5000 nombres, que nos pregunta qué estamos pensando y que nos insta a visitar perfiles afines requiere la anuencia de sus usuarios, que asumen las reglas del juego a sabiendas de la manipulación inherente al medio.

Los poetas actuales también manifiestan una ambivalente actitud de atracción y repulsa ante las redes sociales. Si estas son una mera réplica de la amistad, aquellos persisten en un cínico autoengaño que los lleva a asomarse al tedio vital parapetados tras los muros de Facebook. Prueba de ello son dos poemas de La huida hacia delante (2014), de Víctor Peña Dacosta (Plasencia, Cáceres, 1985), en los que combaten las apariencias y la verdad, la voluntad individual y las expectativas públicas. En tanto que "Antirretrato" termina con el corolario contrarrevolucionario "Ya ni Facebook se altera / con mis golpes de estado" (2014: 36), "Adaptación al miedo" deforma un concepto perteneciente a la biología para acatar los signos superficiales de la madurez: "Medir la vida en estados de Facebook / y la aceptación social en 'me gustas"' (77). No muy distinta es la actitud de Berta García Faet (Valencia, 1988) cuando parodia los clichés del sentimentalismo adolescente en versos como "una vez chateamos por facebook

\footnotetext{
${ }^{10}$ La actualización tópica que conlleva la referencia a Internet afecta a otros temas, como el paso del tiempo -“En mi reloj del móvil las seis de la mañana” "“Discoteca”, de Gonzalo Gragera) - o el quevedesco amor constante más allá de la muerte -"Y pasarán los años, y llegará la muerte, / y apagará el router y el mundo será / un teatro monstruoso. // Pero yo / quiero crear hipervínculos contigo [...]” (“Tú me haces decir wow!”, de Sergio C. Fanjul)-.
} 
durante ocho horas / y amaneció y sentí que la vida era esto" (en Floriano y Rivero Machina, 2016: 149). ${ }^{11}$

La desprejuiciada reapropiación lírica de las redes sociales constituye la médula de Pertinaz freelance (2016), de Sergio C. Fanjul (Oviedo, 1980), una desenfrenada orgía virtual que, desde su dedicatoria inicial a Mark Zuckerberg, recicla el código de las nuevas tecnologías en una sintaxis en la que convergen emoticonos, mensajes móviles, videojuegos, odas al WhatsApp y canciones ciberdesesperadas. El poema que abre el libro, "Alicia en el País de las Redes Sociales", puede leerse como un manifiesto del cibernauta absorbido por el cristal de la pantalla y cautivado por la imagen especular que se refleja al otro lado. En este caso, la Alicia que salta por las ventanas de las redes sociales desde el amanecer hasta la noche es a la vez una versión rediviva del personaje inmortal de Lewis Carroll, un desdoblamiento de la amada-ciberadicta y un correlato subjetivo que se entrega al fervor de Internet:

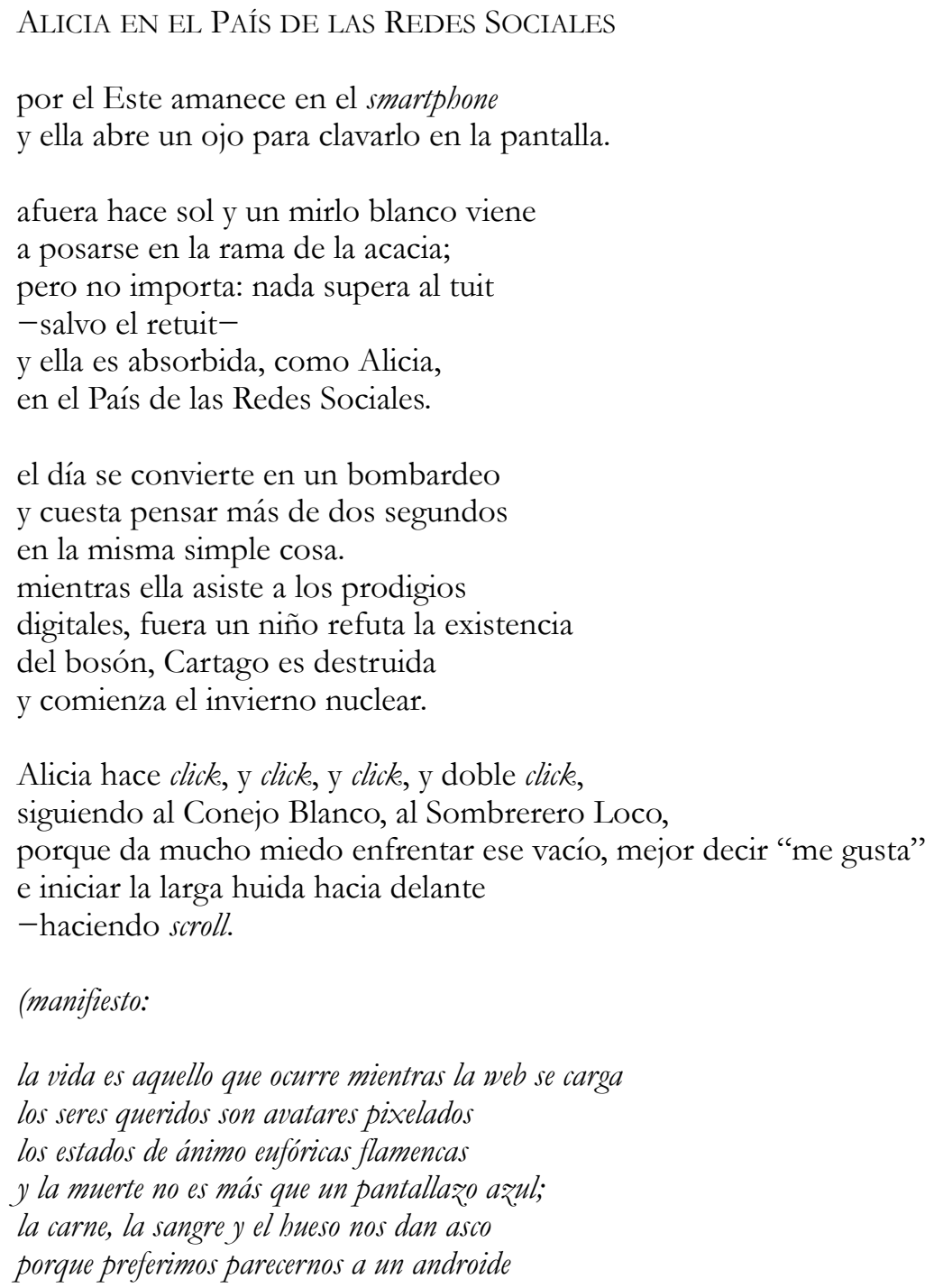

11 La misma función desautomatizadora se observa en "A un poeta de Twitter" (Fuego cruzado, 2014), de Xaime Martínez (Oviedo, 1993), que especula con irreverente sarcasmo sobre un romance imposible entre el papa Benedicto XVI y el poeta-tuitero Carlos Salem. 
que a un cocido madrileño)

ajeno a todo esto, el sol, que es analógico, se derrumba y anochece, y Alicia se despide cariñosa de su smartphone. antes de apagar la lucecita piensa que ya solo quedan ocho horas:

con un poco de suerte, suspira, soñará con un estado de Facebook que cambiará el mundo. pero en su sueño reina la Reina de Corazones, que grita ique le corten la cabeza!

(Fanjul, 2016: 9-10)

Este tratado de la nueva servidumbre digital admite diversos niveles de lectura. Desde su título, la composición toma como hipertexto las novelas de Lewis Carroll Alicia en el país de las maravillas (1865) y A través del espejo (1872). A esta plantilla remiten la mención explícita de ciertos personajes (el Conejo Blanco, el Sombrerero Loco, la Reina de Corazones), la frase favorita de la Reina de Corazones ("ique le corten la cabeza!") e incluso la dispersión de la estructura discursiva, que dialoga con el fragmentarismo de los libros de Carroll. Como apunta SánchezMesa (2010: 120), estos últimos “eran ya en sí mismos poco ortodoxos en cuanto 'narrativas' por cuanto ofrecían una sucesión más o menos inconexa de episodios no ligados por principios de la lógica causal o de la verosimilitud". Sin embargo, existe una diferencia sustancial entre la Alicia de Carroll y la de Fanjul: la fantasía onírica no es ahora un reverso del mundo cotidiano, sino una extensión de sus posibilidades. La perfección geométrica del smartphone, el clic compulsivo, el scroll de la pantalla, el retuit de Twitter y los estados de Facebook pertenecen a un régimen diurno más atractivo que el universo de los sueños cuya puerta falsa descubre Alicia. Los "prodigios / digitales" a plena luz del día desempeñan una doble misión. Por un lado, las redes sociales se conciben como una suerte de mausoleo tecnológico o de caverna neoplatónica que recorta los contornos sombríos de un día soleado: en contraposición a la naturaleza minimalista que convoca el poema (la acacia, el mirlo, el sol), el paisaje electrónico diseña un tapiz belicoso y apocalíptico (un bombardeo, la destrucción de Cartago o el invierno nuclear). Por otro lado, frente a la caducidad que asedia al ser humano, las redes sociales se erigen en un aséptico sucedáneo de la eternidad. La tensión dialéctica entre la vida y la web - para cuya formulación Fanjul retuerce un aforismo atribuido a John Lennon- desemboca en una conclusión desencantada: quizá los trucos y efectos especiales de la Red no sean más que "juegos para aplazar la muerte”, parafraseando a Juan Luis Panero. En este sentido, no parece casual que la única salida de emergencia que contempla Fanjul coincida con el sintagma que daba título al ya referido libro de Víctor Peña Dacosta: "la [larga] huida hacia delante".

Desde este enfoque, las redes sociales actualizan una inquietud metafísica, expresan una desazón generacional y regurgitan los añicos de una subjetividad en crisis. Cuando todo lo sólido se desvanece en el aire, los logotipos de Facebook, Twitter o Instagram se alzan en los estandartes de una resistencia silenciosa, entre el consuelo de la aurea mediocritas y la escenificación barroca del desengaño. Al cabo, las redes no son el paraíso prometido por los apóstoles de la tecnolatría ni el infierno temido por los profetas de lo analógico, sino un espejo público que nos 
expone al escrutinio de los demás internautas y un espejismo que nos invita a evadirnos de las asperezas de la realidad.

\section{NUESTRO GOOGLE DE CADA DÍA: YO NO BUSCO, YO ENCUENTRO}

Mientras que las redes sociales multiplican la intimidad privada a escala global, los almacenes de Internet custodian una copia en caché de nuestra memoria colectiva: "en esos hangares de Google que alojan terabytes de información está la memoria del planeta, y la memoria es buena parte de la identidad" (Mora, 2012: 41). Al igual que ocurría con los universos paralelos de Facebook o Twitter, los buscadores de la Red diseñan un nuevo modelo de interacción que podría reducirse al eslogan "Eres en Google" (Molinuevo, 2006: 113, n. 9) o a la célebre sentencia de Picasso: "Yo no busco, yo encuentro". No obstante, si la proteica identidad de las redes sociales afectaba sobre todo a la (auto)percepción individual, la que se canaliza a través de Google es más bien una identidad transaccional que va moldeándose a medida que visitamos los enclaves del ciberespacio. En consecuencia, "somos en Google" porque cada búsqueda nos define como consumidores potenciales y porque los circuitos de Internet han aprendido a rastrear las huellas que dejamos en nuestros merodeos virtuales. Existe así una dependencia recíproca entre lo que queremos de Google y lo que Google quiere de nosotros. Asimismo, gracias a sus numerosas aplicaciones conexas, Google ha pasado de ser una reserva utópica a convertirse en el hipermercado en cuyos pasillos se negocian los intercambios sociopolíticos de la era poscapitalista. 12

Desde el perezoso "voy a tener suerte" -que nos insta a dar a la primera con el resultado deseado- hasta las más complejas pesquisas detectivescas, todas nuestras indagaciones digitales se subordinan al incesante tráfico de datos y a la efervescencia electrónica de los buscadores. Laura Casielles (Pola de Siero, Asturias, 1986) subraya el sometimiento a la dictadura de Google y los peligros que entraña el excesivo afán de conocimiento en un poema que se titula igual que el buscador más famoso de la web:

\section{GOOGLE}

Despedaza las mil tentaciones, no sigas los cantos de las sirenas sordas.

No quieras ver su foto, no quieras detallar su nombre.

Si cometiste el error, si abriste la caja, ahora no quieras saber:

los dioses no te perdonarían un segundo desliz.

\footnotetext{
${ }^{12}$ El paralelismo entre los intercambios sentimentales y las aplicaciones tecnológicas se explota, con contundencia aforística, en versos como "mírame a los ojos y dime cosas que no necesite comprobar en wikipedia" o "quiero que google maps me diga cuánto voy a tardar en sentirme mal cuando pase por delante de tu casa" (Houston, yo soy el problema, 2016), de Óscar García Sierra (León, 1994); y en títulos como "Voy a publicar en Wikileaks todos tus mensajes de whatsapp”(Lloráis porque sois jóvenes, 2016), de Emilio Martín Vargas (Valencia, 1979).
} 
No te atrevas a saber.

No es

asunto

tuyo.

No te preguntes: empezarás a pedir explicaciones.

Quien sabe demasiado

no sabe dormir.

(En VV. AA., 2015: 167)

La épica de nuevo cuño que genera Internet dialoga aquí con la mitología clásica: por una parte, las "sirenas sordas" que pregonan las mercancías virtuales imitan a las sirenas cantarinas que a punto estuvieron de hacer naufragar la expedición de Ulises; por otra, "la caja" de Pandora - afortunada metáfora de la Red de redes- nos recuerda los riesgos a los que conduce una curiosidad ilimitada. Con todo, la reiteración anafórica de órdenes negativas - "No quieras ver su foto", "No te atrevas a saber", "No es / asunto / tuyo", "No te preguntes"- nos invita de manera velada a contravenir dichas prohibiciones y, por tanto, a caer en el error definitivo - el "segundo desliz", tras la conexión a Internet- en el que incurrimos al teclear cualquier nombre en Google. Ese desafío teológico tiene como contrapartida el castigo de la intranquilidad.

Pero Google no es solo Google, sino también su circunstancia; es decir, todas aquellas aplicaciones que le ponen apellido al buscador y que nos animan a profundizar en el relieve de la Red. Algunas de las aplicaciones más populares trasladan a la cartografía hipotética de Internet las dimensiones de la geografía auténtica. El callejero de Google Street View y el mapa planetario de Google Maps ejemplifican ese movimiento de ida y vuelta entre los espacios reales y los territorios clónicos del espacio digital. Precisamente "Google Maps" se titula un poema de Diego Álvarez Miguel (Oviedo, 1990) que funde la evocación de diversos lugares de Londres con la evocación de una relación amorosa:

\section{GOOGLE MAPS}

Desde Torwood Street puede verse el mar inmóvil, las líneas quebradas de las carreteras, las casas bajas, los veleros atracados a lo lejos. Pueden verse las paradas de autobús, las anchas calles por las que pasean mujeres escondiendo el monedero, las terrazas que anuncian english breakfast, fresh juice, la alta noria que me recuerda al London Eye, y el London Eye que me recuerda a nuestro hotel y nuestro hotel que me recuerda a tus pechos cayendo inmensos como las lámparas del palacio de la reina de Inglaterra. Se llega desde Torwood Street presionando la flecha de mi teclado a Parkhill Road, donde me imagino haciéndote el amor toda la noche bajo la lupa inmensa de los internautas y la luna virtual de los satélites -una luna metálica, como un gong-, 
revolcándonos como animales por encima del capó de un Renault mal aparcado justo frente a la farmacia. Quisiera cenar contigo en Kim Saigon, en el Simca y en Maha-Bharat, y en Jingles, que me arda la lengua, bajar por Victoria Parade y ver que el polvo se ha convertido en poco menos que un sueño de calles y puertos deportivos. Quisiera convertirme en ese transeúnte anónimo que el coche de Google pilla infraganti saliendo de un portal que hay a muy pocas manzanas de tu casa. Quisiera cruzarme contigo en alguna de estas calles - en Warren Road o en The Terrace, en Queen Street o en Lime Avenue-, y llenarme la boca con la blueberry muffin que sostienes sorprendida entre las manos. (En Morante, 2016: 244-245)

La convencional historia sentimental que sugieren los versos se contraviene gracias a la connivencia de dos recursos simultáneos: por un lado, la metódica enumeración de calles, monumentos y bares de la capital británica transforma la experiencia erótica en una suerte de periplo turístico; por otro, las remisiones a "la flecha de mi teclado", a los voyeurs cibernéticos ("la lupa intensa de los internautas") o al flâneur anónimo que sale como extra en el barrido cinematográfico de Google dan cuenta del carácter alegórico de ese recorrido. En el desenlace, el travelling de Google Maps logra salvar la distancia que separa a la amada de quien la imagina a través de una pantalla en la que se troquela también la radiografía virtual de una ciudad.

Por último, "Lost in Google Translate", un poema inédito que Víctor Peña Dacosta ha reproducido en su blog, reintegra las aplicaciones de Google en la vertiente metadiscursiva a la que dedicábamos la primera parada de este viaje:

\section{LOST IN GOOGLE TRANSLATE}

Todos queremos que nos encuentren.

Bob Harris

Los alemanes tienen una palabra

para expresar la nostalgia que uno

siente hacia el lugar donde nunca

ha llegado a estar. Es fernweh,

como quiera que se pronuncie.

En inglés tienen varios tipos

de sonrisa: entre ellos, smirk, con pocos

dientes, o grin, con muchos (¿demasiados?).

En algunas lenguas bantúes, ilunga

es quien perdona una misma ofensa

dos veces y a la tercera se enfada.

En tagalo, gigil es el deseo irresistible 
de abrazar a alguien que es muy rico

o muy guapo. $\mathrm{O}$ ambos, a ser posible.

Schadenfreude: dícese de alegrarse

en alemán de las (pequeñas) desgracias ajenas.

Aware es para los japoneses esa

melancolía que se siente

al vivir un momento de belleza

fugaz y trascendente.

Por su parte, Koi No Yokan expresa

cuando conoces a alguien y sientes

que tarde o temprano os vais

a enamorar el uno del otro.

Cafuné, en portugués brasileño,

es el acto de pasar los dedos

a través del pelo de la persona

que amas. Por su parte,

los angloparlantes alucinan

cuando les explicas lo que es la "dentera":

No tienen palabra para ese concepto.

(Peña Dacosta, 2017: s/p)

En tanto que el título y la cita inicial - del personaje interpretado por Bill Murray- suponen un guiño cómplice a la película Lost in Translation (2003), de Sofia Coppola, la mención del traductor automático Google Translate introduce una ruptura de expectativas. Aunque se trata de una herramienta de indudable utilidad, el traductor de Google a menudo nos induce a confusión, pues el motor de dicho programa no siempre es capaz de detectar el sentido que deseamos conferirle a un vocablo polisémico. A partir de esta premisa, el texto de Peña Dacosta recopila un inventario caótico de palabras intraducibles que -aunque apelan a sentimientos universales - solo pueden explicarse en otros idiomas mediante una paráfrasis. El contraste entre la riqueza de matices de las lenguas naturales y las uniformes traducciones automáticas de Google Translate no solo implica una constatación de la diversidad lingüística frente a la homogeneidad de la inteligencia artificial, sino también un alegato a favor de la precisión que cabe exigirle al discurso poético.

En síntesis, la googleratura inspirada por los buscadores refleja las modalidades de interacción entre el usuario y el medio tecnológico. La amenaza de naufragar en la corriente de datos que fluye en Internet (en Casielles), la superposición de la geografía real y la geografía duplicada en el calco de Google Maps (en Álvarez Miguel), o las limitaciones traductológicas de Google Translate (en Peña Dacosta) dan testimonio de las posibilidades que ofrecen las páginas en construcción del entorno digital.

\section{RECAPITULACIÓN: CTRL + ALT + SUPR}

En este artículo se ha pretendido demostrar que la Red ya no atrapa a los poetas de las últimas hornadas por su densidad mitogenética ni por su vecindad con las formas líquidas de la 
cultura pop, en un intento de desestabilizar las rígidas jerarquías de la alta cultura. Si este era el aspecto que más les interesaba a los miembros de las generaciones precedentes, los autores nacidos a partir de los años ochenta no ven en Internet una herramienta subversiva, sino el signo de una identidad comunitaria. A comienzos del siglo XXI, la Red se erige en el paisaje colectivo por el que transitan asiduamente los poetas-cibernautas. Esta experiencia cotidiana les permite naturalizar la presencia de los mundos virtuales en sus obras y utilizar el código de las nuevas tecnologías para abordar asuntos ajenos a la efusión futurista. No en vano, el dialecto de las puntocom funciona como un tamiz irónico para revisitar, actualizar y, al cabo, desacralizar temas eternos como la perduración de la palabra lírica, la precariedad existencial o las transacciones sentimentales.

La reflexión metapoética auspiciada por el lenguaje informático, los simulacros de identidad que se destilan en las redes sociales y las estrategias relacionales que postulan buscadores y aplicaciones han sido los tres enlaces que he procurado desenredar en los apartados anteriores. Una vez incumplidos los fatales presagios milenaristas del efecto dos mil, cabe prever que la Red vaya a continuar apareciendo en los versos de los escritores jóvenes, a veces como correlato alienante de "los mundos sutiles, ingrávidos y gentiles" de los que hablaba Machado y otras veces como espejo de una realidad doliente y hecha pedazos. En cualquier caso, es hora de pulsar "Guardar" y de llevar el puntero hasta la equis blanca que tienen en el vértice derecho de la pantalla. Vale. 


\section{BIBLIOGRAFÍA}

Aguilar, Andrea. "La poesía estalla en las redes”. Babelia (2014).

BAgué Quílez, Luis. "La poesía española bajo el efecto 2000 (dos o tres cosas que sé de ella)". Ínsula, 805-806 [número monográfico dedicado a Poesía española contemporánea] (2014): 5-8.

BAguÉ Quílez, Luis y SANTAmaríA, Alberto (2013). “2001-2012: una odisea en el tiempo”. BAgué Quílez, Luis y SANTAMARÍA, Alberto (eds.). Malos tiempos para la épica. Última poesía española (2001-2012). Madrid: Visor: 11-32.

BreA, José Luis (2007). Cultura_RAM. Mutaciones de la cultura en la era de su distribución económica. Barcelona: Gedisa.

CASIELLES, Laura (2015). "Google". VV. AA. El signo anunciado. La marca en la literatura y el arte [Litoral, 260]. Málaga: Revista Litoral: 167.

CASTELls, Manuel ([1996] 1997). La era de la información. Economía, sociedad y cultura. Vol. 1 La sociedad red. Madrid: Alianza.

Clark, Ben (2011). La mezcla confusa. San Sebastián de los Reyes: Universidad Popular José Hierro.

CORRAL CAÑAS, Celia (2014). Nuevos ámbitos en la creación de arte verbal. Poesía española contemporánea en la Red. Tesis Doctoral: Universidad de Salamanca.

DíAZ Rosales, Raúl (2011). "La construcción del nuevo canon. Internet y comunidades (literarias) de poder". MONTESA, Salvador (ed.). Literatura e Internet. Nuevos textos, nuevos lectores. Málaga: AEDILE: 279-292.

ECO, Umberto ([1964] 1990). Apocalípticos e integrados. Barcelona: Lumen.

Fanjul, Sergio C. (2016). Pertinaz freelance. Madrid: Visor.

FERNÁNDEZ MALlo, Agustín (2012). Blog up. Ensayos sobre cultura y sociedad. Valladolid: Universidad de Valladolid. Ed. de Teresa Gómez Trueba.

Floriano, Miguel y Rivero Machina, Antonio (2016) (eds.). Nacer en otro tiempo. Antología de la joven poesía española. Sevilla: Renacimiento.

FrANCOS, Aitor (2013). Un lugar en el que nunca he escrito. Sevilla: Renacimiento.

GONZÁLEZ, David (2010) (ed.). La manera de recogerse el pelo. Generación Blogger. Madrid: Bartleby.

Jauralde Pou, Pablo. “Poesía española actual en la Red”. Ínsula, 805-806 (2014): 25-28.

LABRADOR MÉNDEZ, Germán. "Poética y ciberespacio. Comunidades de opinión, crítica literaria, discursos culturales y generadores automáticos de poesía en Internet: un estudio aplicado". Cuadernos del Minotauro, 4 (2006): 55-77.

LECHNER, Jan ([1968 y 1975] 2004). El compromiso en la poesía española del siglo XX. Alicante: Universidad de Alicante. 
MARTín Gijón, Mario (2011). "La blogosfera en el campo literario español. ¿Espacios en conflicto o vanguardia asimilada?". MONTESA, Salvador (ed.). Literatura e Internet. Nuevos textos, nuevos lectores. Málaga: AEDILE: 355-366.

MCLuHAN, Mashall ([1964] 1996). Comprender los medios de comunicación. Barcelona: Paidós.

Mohedano RuAnO, Javier. "Escrituras del acervo. Retóricas de lo común en la última poesía española”. Impossibilia, 12 (2016): 158-173.

Molinuevo, José Luis. "La crisis de los nómadas digitales". Taula. Quaderns de Pensament, 40 (2006): 107-122.

MORA, Vicente Luis (2012). El lectoespectador. Deslizamientos entre literatura e imagen. Barcelona: Seix Barral.

MORA, Vicente Luis (2018). "Retórica textovisual y persuasión publicitaria en la poesía española actual”. BAgué Quílez, Luis (ed.). Cosas que el dinero puede comprar. Del eslogan al poema. Madrid / Frankfurt am Main: Iberoamericana / Vervuert: 301-324.

Morante, José Luis (ed.) (2016). Re-generación. Antología de poesía española (2000-2015). Granada: Valparaíso.

PeÑa DACOSTA, Víctor (2014). La buida hacia delante. Sevilla: Isla de Siltolá.

PeÑa DACOSTA, Víctor. “Lost in Google Translate”. Arrebatos Alíricos (2017).

Prieto De Paula, Ángel L. (2010) (ed.). Las moradas del verbo. Poetas españoles de la democracia [antología]. Madrid: Calambur.

Quinto, Raúl (2013). “La poesía después de Internet”. BAgUÉ Quílez, Luis y SANTAMARíA, Alberto (eds.). Malos tiempos para la épica. Última poesía española (2001-2012). Madrid: Visor: 193-206.

RIECHMANN, Jorge (2013). Fracasar mejor (fragmentos, interrogantes, notas, protopoemas y reflexiones). Zaragoza: Olifante.

Rodríguez-Gaona, Martín (2010). Mejorando lo presente. Poesía española última: posmodernidad, bumanismo y redes. Madrid: Caballo de Troya.

Román, Camino. “Cinco poemas de Camino Román”. El Nacional (2017).

Rosal Nadales, María. "La poesía en los tiempos del blog: jóvenes poetas españolas". Sociocriticism, XXXI (1) (2016): 181-207.

SAlgado, María (2010). 31 poemas. Málaga: Diputación Provincial de Málaga.

SÁNCHEZ, María. "Wifi tear us apart again”. Fantastic Mag (2015).

SÁNCHEZ-MESA, Domingo (2011). "Literatura aumentada: intermedialidad / transmedialidad o el viaje de Alicia a través de las pantallas". MONTESA, Salvador (ed.). Literatura e Internet. Nuevos textos, nuevos lectores. Málaga: AEDILE: 109-129.

SCARANO, Laura. "Poéticas de lo menor en la galaxia global". Ínsula, 805-806 (2014): 19-21.

ŽIŽEK, Slavoj (2006). Lacrimae rerum. Ensayos sobre cine moderno y ciberespacio. Madrid: Debate. 